\title{
DA CENA CONTEMPORÂNEA E AS TECNOLOGIAS DIGITAIS
}

\section{LARISSA HOBI. UFPB}

\section{RESUMO}

Partindo do pressuposto de que as artes sempre dispuseram de recursos, suportes e dispositivos pertencentes ao seu contexto de época, pretende-se uma reflexão acerca de composições cênicas mediadas por tecnologias digitais. As possibilidades abertas pelo duplo virtual (internet/web) gerou um tipo de teatro com outra base material e novas formas de organização e estruturação, gerando um deslocamento na lógica da composição teatral, abrindo possibilidades de construções e hibridizações das mais diversas possíveis.

Palavras-chave: Cena contemporânea. Tecnologias digitais. Intermidialidade. Composições Mediadas.

\section{ABSTRACT}

Based on the presupposition that the arts always counted on resources, supports, and devices pertaining to its time context, an reflection is intended regarding the scenic compositions mediated by digital technologies do. The possibilities allowed by the double virtual (Internet/web) generated a type of theater with another material basis and new forms of organization and structure, generating a dislocation in the logics of theatrical composition, thus offering new possibilities of constructions and hybridization of the of the most different possible types.

Keywords: Contemporary scene. Digital technologies. Intermediality. Compositions Mediated.

Com o advento das tecnologias digitais tornaram-se corriqueiras as discussões sobre o futuro do humano e de que forma se estabelecerão as relações referentes à interface humano/máquina. É possível observar a incidência e recorrência da referida temática em diversos âmbitos, como o acadêmico, o social e o cotidiano - a exemplo de livros, palestras, mesas redondas, artigos científicos, filmes, matérias em jornais, blogs, novelas, seriados, desenhos infantis e chats que abordam a humanização das máquinas, a biogenética, a realidade aumentada, a inteligência artificial, etc. Essas questões, antes abordadas apenas pela ficção científica, que especulava de que forma o humano configurar-se-ia no futuro, tem adquirido na contemporaneidade a expressão de uma realidade potencial que transita como "ficção da ciência" e "ciência da ficção".

Estudiosos acreditam que essa projeção no futuro está presente dentro e fora dos seres humanos, tornando-se parte da nossa realidade e auxiliando na reconfiguração da percepção que temos dela, como exemplo podemos apontar 
essas novas presenças que surgem na contemporaneidade e que se efetivam por sua potência e dinâmica adotada por grupos que a concebem como tal. Não se trata mais de relativizar, mas de percebê-la como uma presença possível. Entre os jovens, tratados na literatura como nativos digitais, que são os indivíduos que já nasceram em contato com todos os tipos de aparatos tecnológicos possíveis e imagináveis, essa presença é tão real como outras possíveis presenças. Podemos perceber que os desdobramentos dessas discussões têm repercutido nas diversas áreas do conhecimento humano, encontrando na arte um dos campos férteis para esses questionamentos.

A aceleração tecnológica tem promovido na contemporaneidade uma ruptura gradativa em relação ao entendimento tradicional de conceitos como: tempo, presença, espaço e corpo. Tal aceleração altera modelos e dinâmicas sociais, culturais, morais e éticas. Para Diana Domingues (2003, p. 17):

Hoje, tudo passa pelas tecnologias: a religião, a indústria, a ciência, a educação entre outros campos da atividade humana estão utilizando intensamente as redes de comunicação, a informação computadorizada, e a humanidade está marcada pelos desafios políticos, econômicos e sociais decorrentes das tecnologias. A arte tecnológica também assume essa relação direta com a vida, gerando produções que levam o homem a repensar a sua própria condição humana.

Com a inserção das tecnologias digitais na cena teatral, pode-se optar pelo deslocamento de elementos antes previstos para estarem presentes no mesmo espaço. Dessa forma, o ator, indispensável ao fenômeno teatral, pode estar presente tanto de forma física como de forma virtual, não se tratando apenas de simulação, mas de presença virtual no real. É possível também relativizar a presença do espectador, que se encontraria deslocado fisicamente do lugar de apresentação do artista. Outra perspectiva é a fragmentação do espaço cênico. Essas modalidades eram impensadas antes das possibilidades abertas com 0 surgimento das redes telemáticas.

Este artigo, tem como fulcro a discussão sobre a cena que incorpora ou se perfaz em eventos intermidiáticos no contexto de uma expansão tecnológica que não para de avançar, encontrando no teatro um terreno propício para investigar 
quais as relações que se estabelecem na cena contemporânea a partir do contágio ocasionado pelas tecnologias digitais.

Como se porta o ator em cena com o uso de uma mídia que se interpõe? Ocorre de fato uma (re)configuração dos elementos narrativos em composições cênicas mediadas? Como se dá o processo de criação? As intervenções da plateia se efetivam? Existe um cuidado em relação à concorrência da presença física com a imagética? Como trabalhar com o espaço cênico desterritorializado? É pensado o imprevisto e a potência performática da tecnologia nessas proposições cênicas?

Propomos uma discussão acerca da intersecção cena contemporânea e tecnologias digitais, inserindo-a em seu contexto de época, levando em conta a convergência das mídias, fenômeno que abriu novas possibilidades, antes impensadas, e que vem pondo em xeque o paradigma teatral - atuante, texto, público. A partir de tais possibilidades emergiram discussões acerca do teatro que incorpora ou se perfaz em eventos mediados tecnologicamente.

Norteando esta discussão está a hipótese da arte como ponto de convergência para se pensar as mutações em âmbito social e cultural. Partimos do pressuposto de que a arte no ocidente sempre se utilizou de recursos, suportes e dispositivos referentes ao seu contexto de época, é possível perceber a mesma dinâmica com as tecnologias digitais, que entraram de forma imperativa em todas as relações da vida cotidiana, sendo desta forma, um dos fatores impulsionadores do desejo por uma estética híbrida que prevê a interface cena/tecnologia, gerando um deslocamento na lógica da composição teatral, iniciado com as vanguardas artísticas, que vem se intensificando gradativamente, abrindo possibilidades de construções e hibridizações das mais diversas possíveis.

Para se produzir arte, sempre houve a utilização da técnica, pois essa se define como um saber fazer, a destreza, a habilidade para se executar ou fazer algo, procedimentos que podem ser aprendidos, desenvolvidos e criados. Até a revolução industrial, as técnicas artísticas dominantes eram artesanais e só a partir de tal evento, com a criação da máquina fotográfica, é que se tem o nascimento das artes tecnológicas, acabando-se dessa forma o exclusivismo das técnicas artesanais. Segundo Santaella (2008, p. 152 - 153):

Enquanto a técnica é um saber fazer, cuja natureza intelectual se caracteriza por habilidades que são introjetadas por um 
indivíduo, a tecnologia inclui a técnica, mas avança além dela. Há tecnologia onde quer que um dispositivo, aparelho ou máquina for capaz de encarnar, fora do corpo humano, um saber técnico, um conhecimento científico acerca de habilidades técnicas especificas. Nessa medida, a arte tecnológica se dá quando o artista produz sua obra através da mediação de dispositivos maquínicos, dispositivos estes que materializam um conhecimento cientifico, isto é, que já tem uma certa inteligência corporificada neles mesmos.

Desde seu surgimento, o vídeo ganha inserção na cena teatral, porém, é com o advento da convergência das mídias - desenvolvimento da multimídia que produziu a convergência de vários campos midiáticos tradicionais em um único formato, o digital; fenômeno que abriu novas possibilidades, antes impensadas - e suas infinidades de usos, que as mídias audiovisuais tem tornado-se quase que uma constante nas encenações contemporâneas. Quais os usos e suas possibilidades? As mídias audiovisuais podem se apresentar de diversas maneiras, sendo solicitada por vezes na composição da cenografia, ou ainda no auxílio a construção da narrativa, como também para presentificar ausentes, efetivar soluções cênicas, como pode também discutir presenças possíveis e conectar lugares distantes geograficamente, por meio de streaming.

$\mathrm{Na}$ atualidade, ocorre uma explosão por meio de inúmeras experiências estéticas, em que a assimilação ou recusa de outras mídias dá-se a partir de propostas diversificadas de encenação e, dessa forma, observa-se que com as mídias digitais ocorre a mesma dinâmica, no qual alguns diretores, companhias e grupos se apropriam de tais elementos tornando-os parte constituinte de suas encenações, agregando e/ou "profanando" (AGAMBEN, 2007) as possibilidades oferecidas pelas tecnologias digitais.

Para tratar do contágio das artes pelas tecnologias digitais, utilizamos da divisão das eras culturais proposta pela autora Lucia Santaella (2008) em seu livro Culturas e artes do pós-humano: da cultura das mídias à cibercultura, em seis tipos de formação não lineares, nas quais na contemporaneidade todas coexistem e dialogam entre si, a saber: Cultura Oral, Cultura Escrita, Cultura Impressa, Cultura de Massa, Cultura das Mídias, Cultura Digital ou Cibercultura. Detivemo-nos nas duas últimas formações culturais.

$\mathrm{Na}$ era da cultura das mídias que se deu na década de 1980 com o surgimento de novas máquinas, equipamentos e produtos midiáticos como 
fotocopiadoras, Walkman e videocassete, que apresentam uma lógica distinta dos meios de massa característicos da era industrial, pois geram um uso individualizado, no qual o sujeito opta pela programação (música, filme, canal, etc.), desenvolveram-se novos processos comunicacionais. Procedimento que a autora considera como "cultura do disponível e do transitório".

Já a cultura digital ou cibercultura dá-se com a possibilidade aberta pelo computador de converter as mais variadas informações - texto, som, imagem, vídeo - em uma linguagem universal. Tal linguagem foi possível a partir da convergência das mídias, desenvolvimento da multimídia que possibilitou converter vários campos midiáticos tradicionais, antes incompatíveis por utilizarem suportes distintos, em um único formato, o digital, "realizável em qualquer tempo e espaço". Desde então, todos podem ser produtor, criador, compositor, apresentador e difusor de seus trabalhos, tornando a cibercultura a cultura do acesso.

\begin{abstract}
Através da digitalização e da compreensão de dados que ela permite, todas as mídias podem ser traduzidas, manipuladas, armazenadas, reproduzidas e distribuídas digitalmente produzindo o fenômeno que vem sendo chamado convergência das mídias. Fenômeno ainda mais impressionante surge da explosão no processo de distribuição e difusão da informação impulsionada pela ligação da informática com as telecomunicações que redundou nas redes de transmissão, acesso e troca de informações que hoje conectam todo o globo na constituição de novas formas de socialização e de cultura que vem sendo chamada de cultura digital ou cibercultura. (SANTAELLA, 2008, p. 60).
\end{abstract}

Tais possibilidades impulsionaram o desenvolvimento das hiper-redes multimídias de comunicação interpessoal as quais, por sua vez, por meio das misturas de meios tecnológicos, como a informática e a teleinformática, junto à convergência das mídias, favoreceram a hibridização das mais diversas ordens no campo artístico, no que se convencionou chamar ciberarte.

Posto isso, propomos refletir como as tecnologias contribuem e alteram o modo de se fazer arte e também a nossa percepção, vivência e relações com os outros e conosco, já que com o advento das tecnologias surgem também novas possibilidades que irão pôr em xeque conceitos relativos à presença, tempo, espaço, corpo. Isso, para alguns autores, gera a realidade expandida que por 
consequência gera o que Cohen (2002) denominou nas artes cênicas "novas arenas de representação". Segundo o autor:

A criação de novas arenas de representação com a entrada, onipresente, do duplo virtual das redes telemáticas (WEBInternet), amplifica o espectro da performação e da investigação cênica com novas circuitações, navegação de presenças e consciências na rede e criação de interiscrituras e textos colaborativos. Com uma imersão em novos paradigmas de simulação e conectividade, em detrimento da representação, a nova cena das redes, dos lofts, dos espaços conectados, desconstrói os axiomas da linguagem teatro: atuante, texto, público - ao vivo, num único espaço, instaurando o campo do Pós-Teatro. A relação axiomática da cena: corpo-texto-audiência, enquanto rito, totalização, implicando interações ao vivo é deslocada para eventos intermediáticos onde a telepresença (on line) espacializa a recepção. (COHEN, 2002, p. 01).

O teatro sempre se valeu de tais recursos, o que ocorre na contemporaneidade, dentro desse atual contexto em que um turbilhão de informações e tecnologias digitais se atualiza em uma velocidade vertiginosa é uma ampliação dessas possibilidades, podendo citar como exemplo o teatro que faz uso das mídias, as artes performáticas, a arte cibernética, dentre outras, que se utilizam dos avanços tecnológicos nas áreas da biotecnologia, da robótica, engenharia molecular, nanotecnologia, tecnologias computacionais em suas criações artísticas.

A encenação, no sentido ao qual atribuímos o termo contemporaneamente, existe há mais de cem anos e mudou de forma radical a nossa concepção do teatro, apresentando-se como componente da história e evolução da peça, de seu sentido e apresentando-se como uma via de compreensão.

[...] a encenação, pelo menos aquela consciente de si mesma, surgiu quando parecia ser necessário mostrar no palco de que maneira o encenador poderia indicar a forma de ler uma obra dramática, que se tornou muito complexa para ser decifrada de maneira única, por um público homogêneo. A encenação dizia respeito, nessa circunstancia, a uma obra literária, e não importa a qual espetáculo visual. Ela surgiu num momento de crise da linguagem e da representação, uma crise como tantas outras que o teatro conheceu. (PAVIS, 2010, p. 45). 
Ocorreram dois fenômenos, derivados da revolução tecnológica, como nos aponta Roubine (1998), que foram de suma importância para o surgimento do encenador, a saber: o apagamento da noção de fronteiras e distâncias; e a descoberta dos recursos da iluminação elétrica.

Apesar dos precedentes históricos ligados ao próprio exercício da cena, seria o caso de reservar o termo encenação, e mais ainda o encenador, para as experiências cênicas a partir dos anos de 1880 , visto que a era dos encenadores não começou antes da crítica radical ao teatro feita por Zola ou Antoine, da mesma maneira que não começou "nem antes" da contra-proposta do simbolismo [...]. (PAVIS, 2010, p. 02).

A junção do desejo de mudança apontado pelos intelectuais do teatro - a exemplo da exploração dos recursos da teatralidade e recusa da representação ilusionista reivindicada pelos simbolistas - à revolução tecnológica, que disponibilizava ferramentas técnicas para alavancar tal desejo, tornaram viável a evolução do espetáculo teatral.

[...] pode-se constatar que a condenação das práticas dominantes da época por alguns intelectuais do teatro não teria sido por si só suficiente, por mais veemente que fosse, para fazer surgirem as transformações que viriam a caracterizar o teatro moderno. Seria mais exato, sem dúvida, dizer que essas transformações se concretizaram [...] graças a coexistência de um desejo de ruptura e de uma possibilidade de mudança. Em outras palavras, as condições para uma transformação da arte cênica achavam-se reunidas, porque estavam reunidos, por um lado 0 instrumento intelectual (a recusa das teorias e formulas superadas, bem como propostas concretas que levavam a realização de outra coisa) e a ferramenta técnica que tornava viável uma revolução desse alcance: a descoberta dos recursos da iluminação elétrica. (ROUBINE, 1998, p. 21-22).

Se traçarmos tendências as quais o teatro se vinculou depois do surgimento da encenação, observamos que tal evolução, percebida não como uma supressão de formas antigas por novas, mas sim como um constante diálogo de influências recíprocas associadas às possibilidades trazidas pela evolução tecnológica e a expansão de suportes, recursos e dispositivos, constatamos que foram gestadas 
propostas estéticas que enfatizam elementos diversos, a exemplo da iluminação, do espaço cênico, da emancipação da prática cênica em relação ao texto e seu autor, a formação sistemática do ator, a autonomia da cena, o teatro enquanto arma histórica e política, o teatro antropológico, o minimalismo, etc., proposições que coexistem na contemporaneidade, dialogam e se aplicam de acordo com as propostas estéticas e/ou políticas almejadas, e muitas vezes integram de forma hibrida um mesmo espetáculo.

A encenação é, assim, uma representação feita sob a perspectiva de um sistema de sentido, controlado por um encenador ou por um coletivo. É uma noção abstrata e teórica, não concreta e empírica. É a regulagem do teatro para as necessidades do teatro e do publico. A encenação coloca o teatro em prática, porém de acordo com um sistema implícito de organização de sentido. (PAVIS, 2010, p. 03).

$\mathrm{Na}$ contemporaneidade, as linhas que demarcam e rotulam as artes tornamse cada vez mais tênues, sendo difícil distinguir e enquadrar alguns fenômenos artísticos em rótulos pré-existentes e bem definidos, as linguagens cada vez mais hibridas dialogam com áreas outras, a exemplo das neurociências, ciências humanas, da robótica, da informática, dentre outras. Muitas vezes ao sairmos de um espetáculo somos surpreendidos pela dúvida. O que acabamos de assistir se tratava de um espetáculo de dança? De teatro? De uma performance? Por um determinado momento nos sentimos participantes de uma instalação, seria isso? Enfim, acreditamos não caber mais aos espectadores e aos críticos indagar-se sobre determinados aspectos tentando enquadrá-los em "caixinhas", precisamos conceber e fruir em uma perspectiva que extrapola as noções de limite do teatro, dando lugar a uma ideia de polifonia.

O que é teatro? Como conceituá-lo? Existe uma única resposta ou, como o concebemos e o percebemos, associa-se às nossas referências, aos nossos préconceitos? O conhecimento teatral espirala dentro e fora do universo do fenômeno teatral, reconstituindo tanto este universo como a si mesmo como uma parte integral deste processo. O discurso teatral e os conceitos, teorias e descobertas das outras áreas de conhecimento continuamente circulam dentro e fora daquilo de que tratam. Assim fazendo, eles reestruturam reflexivamente ${ }^{1}$ seu objeto. 
Pavis (2010, p. 54) ventila uma convergência epistemológica de encenação e performance: "A partir do último decênio do século XX, a tendência à aproximação de encenação e performance aproximou-se".

O termo performance assume na contemporaneidade uma gama diversificada de significações utilizadas para designar fenômenos variados na literatura, nas artes e nas ciências sociais. Com a crescente utilização do termo em áreas distintas, surge também uma riqueza conceitual, que gera nuances semânticas por meio de uma dialética/dialógica acerca da conceituação do termo performance. Carlson (2009) aponta que, na contemporaneidade as manifestações performáticas se apresentam, tanto na teoria quanto na prática, de formas variadas e em grande quantidade, sendo praticamente impossível um completo mapeamento delas. Distinguindo dois conceitos possíveis de performance:

[...] um envolvendo a exibição de habilidades, e outro também abrangendo exibição, mas menos de habilidades do que de modelo de comportamento reconhecido e codificado culturalmente $^{2}$. Um terceiro conjunto de usos do termo nos leva a uma direção diferente [...] a ênfase não está na exibição de habilidades (embora isso possa estar presente) ou na execução de um determinado modelo de comportamento, mas no sucesso da atividade, tendo em vista algum padrão de realização que não precisa estar articulado com precisão. Talvez seja mais significativo que a tarefa de julgar o sucesso do performer (ou mesmo de julgar se é uma performance), nesses caos, não é de responsabilidade do performer, mas do observador. (CARLSON, 2009, p. 15).

Como nos apresenta Carlson (2009) vários eventos ligados a acontecimentos vanguardistas influenciaram e foram importantes para a consolidação da arte de performance, como: Dadaísmo, Surrealismo, Futurismo, happening, body art, Fluxus.

É inquestionavelmente correto traçar uma relação entre a arte de performance muito mais moderna e a tradição de vanguarda da arte e do teatro do século 20 , já que muito da arte de performance tem sido criada e continua a operar dentro daquele contexto. Mas, concentrar-se ampla e exclusivamente no aspecto vanguardista da arte de performance moderna, como muitos escritores o fizeram, pode limitar a compreensão tanto do funcionamento social 
dessa arte hoje como do modo como ela se relaciona a outra atividade performativa do passado. (CARLSON, 2009, p. 94).

Apesar disso, Carlson (2009) nos alerta para a necessidade de relacionarmos a performance moderna com atividades de performance mais antigas, fenômenos esses que não estão dissociadas de ações performativas, mas que levam em conta não "as limitações de formas artísticas existentes" (CARLSON, 2009, p. 94-95) ou ainda como muitas propostas da performance "a presença física", mas sim uma "[...] presença para o artista na sociedade, uma presença que pode ser esotérica, xamanística, instrutiva, provocativa ou de entretenimento". Apontando assim, outra forma de apreender a evolução da arte performática, levando em conta atividades de entretenimento ou arte, produzidas conscientemente para uma audiência em contextos históricos distintos, a exemplo de músicos, mímicos, acrobatas no período clássico; ou, trovadores, poetas, menestréis, charlatões e os jograis da Idade Média; como também os músicos ambulantes das feiras medievais e renascentistas; e ainda, o circo, o vaudeville, os shows de variedades, os music halls e os cabarés ao longo do século XIX, dentre outros.

É importante evidenciar, como nos aponta Glusberg (1987, p. 42-43), que a performance surge como um gênero mais amplo que agrupa diversas propostas que tinham como denominador comum "[...] desfetichizar o corpo humano eliminando toda exaltação à beleza a que ele foi elevado durante séculos pela literatura, pintura e escultura - para trazê-lo à sua verdadeira função: a de instrumento do homem, do qual, por sua vez, depende o homem." Porém, vai além, pois apresenta-se como uma prática que:

[...] Apesar de utilizar o corpo como matéria-prima, não se reduz somente à exploração de suas capacidades, incorporando também outros aspectos, tanto individuais quanto sociais, vinculados com o princípio básico de transformar o artista na sua própria obra, ou, melhor ainda, em sujeito e obra de sua arte. (GLUSBERG, 1987, p. 43).

A encenação contemporânea trabalha com elementos que tangenciam o panorama epistemológico da performance - sua trajetória evolutiva, seus paradigmas estruturais, suas variações semânticas e suas relações com a 
sociedade - promovendo um diálogo e uma contaminação mútua entre objetos estéticos instáveis, fluídos, que retratam e refletem o momento social ao qual nos encontramos inseridos, descrito por Bauman (2001) através da metáfora da fluide $z^{3}$, que é a qualidade dos líquidos e gases, que sofrem mudanças constantes ao serem submetidos a tensões.

[...] a performance theory e a renovação da prática teatral revelam-nos as noções outrora incompatíveis de performance e encenação. Esta aproximação é tão marcada que seria preciso quase que criar palavras híbridas, como, mise-en-perf ou performise. O diagnostico desta contaminação é simples: não saberíamos, no momento, criar uma encenação sem a reflexão da performance theory, nem uma performance sem a possibilidade de se fazer uma análise semiológica e fenomenológica. (PAVIS, 2010, p. 60).

A Encenação, outrora fechada em seus mecanismos de regulagem voltados para transposição e ilustração do texto, flerta atualmente com traços estilísticos atribuídos inicialmente à performance, buscando dessa forma não uma substituição do termo, mas uma complementação. Na contemporaneidade, devido ao hibridismo e confluência das diversas artes, a noção de encenação se expande enriquecendoa e diversificando-a, o que nos obriga, como propõe Pavis (2010, p. 390) "a repensar o mecanismo de regulagem que preside a criação estética desse objeto chamado encenação".

Retomando a hipótese da arte como ponto de convergência para se pensar as mutações em âmbito social e cultural, sugerimos que essas possibilidades preconizadas pela encenação, sua evolução contínua, seu diálogo com as demais áreas artísticas e do conhecimento, possibilitaram as experiências relativamente recentes do teatro com as tecnologias digitais.

Considerando a arte como ponto de convergência para se pensar as mutações em âmbito social e cultural é possível perceber que tais avanços tecnológicos e as artes se contaminam mutuamente, gerando um deslocamento na lógica da composição teatral. Movimento esse, iniciado com as vanguardas artísticas e que vem se intensificando gradativamente, abrindo possibilidades de construções e hibridizações das mais diversas possíveis.

Por meio do entrecruzamento e das contaminações emergem propostas estéticas que tecem relações entre mídias distintas que, através do diálogo desses 
entrelaçamentos, proporcionam um tencionamento paradigmático. É nesse lugar limítrofe onde as mídias confluem que ocorre entre as artes/tecnologias uma apreensão mútua de recursos e formas de estruturação.

As possibilidades abertas pelo duplo virtual (internet/web) gerou um outro tipo de teatro, com outra base material e novas formas de organização e estruturação, atestando "a maneira pela qual as mídias (exteriores à obra cênica) se integram a materiais da representação utilizando propriedades historicamente atestadas dessas mídias de origem e tomando então, nesse novo contexto, uma dimensão bem diferente" (PAVIS, 2005, p. 43), caracterizando os desdobramentos das novas formas de intermidialidade trazidas com os avanços tecnológicos. Porém, tais mudanças levantam questões se tais produções seriam um gênero teatral ou se configurariam como uma "submídia" da mídia teatro.

Por se tratar de uma discussão relativamente recente e de composições intermidiáticas, gera dúvidas e questionamentos acerca do que se produz. Uma variedade de termos tem sido sugerida para designar tal fenômeno, como: ciberteatro, teatro digital, teatro tecnológico, teatro high-tech, dentre outros. Junto com os rótulos, diversos debates tem emergido, uns pautados na utilização das tecnologias de forma ilustrativa ou como suporte, outros, apontando as transformações advindas por estas propostas, como também, possíveis usos de tais tecnologias apontado por teóricos.

$\mathrm{Na}$ atualidade, vivemos sob o domínio da velocidade, da superficialidade. Vivemos hoje on e off line o tempo todo, podendo recorrer ao uso da telefonia móvel que nos permite estar constantemente entre redes, para ilustrar tal fenômeno. Como se porta o teatro diante das dificuldades com as quais ciclicamente é confrontado? Ao teatro cabe refletir-se, criar estratégias que dialoguem com suas plateias habituadas as imagens em movimento, na qual a percepção se pauta na simultaneidade. Enfatizamos que o surgimento de novas possibilidades, a exemplo das advindas das tecnologias digitais, não anula formas e estéticas já consagradas, surgem para somar, dialogar.

Não se trata de postular um "novo teatro", colocado acima ou significando a superação das formas tradicionais de expressão cênica. Trata-se, isso sim, de um debruçar-se sobre um meio de manifestação que encontrou no espaço cênico um fértil terreno para sua evolução e que, de maneira intensa e crescente, está a abrir 
novas frentes de discussão sobre o papel e o alcance das formas dramáticas estabelecidas.

Devido à revolução tecnológica, iniciada no século XIX, vivenciamos hoje, de forma concreta, real o encurtamento de distancias e a ideia de fronteiras atenuadas. Como também, as discussões de temáticas tradicionais ao fazer teatral, buscando estabelecer novos parâmetros para solucionar questões oriundas das dicotomias - presente/ausente; ao vivo/ midiático; material/irreal; humano/inumano - as quais o teatro por muito se inseriu.

A revolução potencial, que as tecnologias digitais trazem consigo, enriquecem as teorias do espetáculo com um novo polo de reflexão e de experimentação, abrindo novas frentes e possibilidades estéticas, afinal, movimentos isolados surgem em espaços distintos simultaneamente. Esse é o legado da convergência das mídias, do disponível e transitório, dos suportes compatíveis e acessíveis a praticamente todas as pessoas.

\begin{abstract}
Podemos estimar que o confronto cotidiano com as mídias do telefone à televisão passando pelo cinema, o vídeo, a fotografia, o computador ou... a escrita - influencia a nossa maneira de perceber e conceitualizar a realidade e que nós percebemos também a realidade espetacular de modo diverso do que há vinte, cinquenta ou cem anos. O impacto dessas mutações não é tanto fisiológico quanto neurocultural: nossos hábitos de percepção mudaram, ainda mais que nossa maneira de produzir e receber teatro evoluiu. (PAVIS, 2005, p. 41).
\end{abstract}

A tomada de consciência pode ser lenta, as resistências tenazes. Porém, o teatro precisará se redefinir, não apenas em uma perspectiva estética, mas em relação a sua própria identidade e finalidade, ao ser colocado em confronto com as tecnologias digitais; como já Ihe foi solicitado em outras circunstâncias.

\title{
REFERÊNCIAS
}

AGANBEN, Giorgio. Profanações. São Paulo: Boitempo, 2007.

BAUMAN, Zygmunt. Modernidade Líquida. Rio de janeiro: Jorge Zahar, 2001.

BERTHOLD, Margot. História mundial do teatro. 3. ed. São Paulo: Perspectiva, 2006. 
CARLSON, Marvin. Performance: uma introdução crítica. Belo Horizonte: UFMG, 2009.

COHEN, Renato. Performance como linguagem. São Paulo: Perspectiva, 1989.

. Work in progress na cena comtemporânea. São Paulo: Perspectiva, 2006.

Pós-teatro: performance, tecnologia e novas arenas de representação.

Disponível em:

$<$ www. itaucultural.org.br/proximoato/Papers/Texto\%20PORT\%20renato\%

20cohen.doc>. Acesso em: 13 abr. 2009.

DOMINGUES, Diana. Arte e vida no século XXI: tecnologia, ciência e criatividade. São Paulo: UNESP, 2003.

GLUSBERG, Jorge. A arte da performance. São Paulo: Perspectiva, 1987.

PAVIS, Patrice. A Encenação contemporânea: origens, tendências, perspectivas. São Paulo: Perspectiva, 2010.

. A análise dos espetáculos. São Paulo: Perspectiva, 2005.

ROUBINE, Jean-Jacques. A linguagem da encenação teatral, 1880 - 1980. 2. ed. Rio de Janeiro: Jorge Zahar, 1998.

SANTAELLA, Lucia. Culturas e artes do pós-humano. 3. ed. São Paulo: Paullus, 2008.

1 "[...] consiste no fato de que as práticas sociais são constantemente examinadas e reformadas à luz de informação renovada sobre estas próprias práticas, alterando assim constitutivamente seu caráter". (GIDDENS, 1991, p. 45).

${ }^{2}$ Esse tipo de performance constitui o que Richard Schechner define como "comportamento restaurado". Segundo Carlson (2009, p. 14), “[...] título sob o qual ele agrupa ações conscientemente separadas da pessoa que as executa - teatro ou outros 'papeis lúdicos', transes, xamanismo, rituais. O conceito utilitário de 'comportamento restaurado' de Schechner aponta para uma qualidade da performance não envolvida com a exibição de habilidade, mas sim com uma certa distância entre o self e o comportamento, análogo àquele que existe entre um ator e o papel que ele encena no palco. Mesmo se uma ação é idêntica à outra na vida real, no palco, ela é considerada 'performada' e, fora do palco, apenas "realizada"'.

3 "O que todas essas características dos fluidos mostram, em linguagem simples, é que os líquidos, diferentemente dos sólidos, não mantêm sua forma com facilidade. Os fluidos, por assim dizer, não fixam o espaço nem prendem o tempo. Enquanto os sólidos têm dimensões espaciais claras, mas neutralizam o impacto e, portanto, diminuem a significação do tempo (resistem efetivamente a seu fluxo ou o tornam irrelevante), os fluidos não se atem muito a qualquer forma e estão constantemente prontos (e propensos) a mudá-las; assim, para eles, o que conta é o tempo, mais do que o espaço que lhes toca ocupar; espaço que, afinal, preenchem apenas "por um momento". Em certo sentido, os sólidos suprimem o tempo; para os líquidos, ao contrário, o tempo é o que importa. Ao descrever os sólidos, podemos ignorar inteiramente o tempo; ao descrever os fluidos, deixar o tempo de fora seria um grave erro. Descrições de líquidos são fotos instantâneas, que precisam ser datadas". (BAUMAN, 2001, p. 08). 